\title{
CHARACTERISTIC OF FROZEN-THAWED EPIDIDYMAL SPERMATOZOA AND REFRIGERATED STORAGE OF RAM SPERMATOZOA
}

\author{
N.W. K. Karja ${ }^{1,2}$, E.M. A. Respaty ${ }^{1}$, I. Nuraini ${ }^{1}$; S.A.Prihatno ${ }^{1}$ and S. Gustari ${ }^{1}$ \\ 1Department of Reproduction and Obstetrics, Faculty of Veterinary Medicine, \\ Gadjah Mada University, Yogyakarta 55281- Indonesia \\ ${ }^{2}$ Present address: Department of Veterinary Clinic, Reproduction and Pathology, \\ Faculty of Veterinary Medicine, Bogor Agricultural University, \\ Jl Agatis Darmaga Campus, Bogor 16680, Indonesia \\ Corresponding E-mail:karja_nwk@yahoo.com
}

Received November 10, 2009.; Accepted February 24, 2010

\begin{abstract}
Post-mortem spermatozoa recovery is an important technique for obtaining germplasm reserves from genetically valuable animals or endangered species. The purpose of this study was to study whether ram spermatozoa within epididymides stored at $4^{\circ} \mathrm{C}$ for 24 and $48 \mathrm{~h}$ remain their motility and viability. The characteristic of ram epididymal spermatozoa after freezing and thawing was also observed. Six pairs of ram testes with attached epididymides were used in this study. The motility of control spermatozoa was well maintained throughout the dilution procedure $(83.3 \pm 1.1,80 \pm 1.3$, and $80 \pm 1.3 \%$ for collection, Niwa and Sasaki freezing -1 extender (NSF-1 and NSF-2 groups respectively); but declined $(\mathrm{P}<0.05)$ after freezing and thawing $(38.3 \pm 3.1 \%)$. Motile and viable spermatozoa could be recovered from epididymides up to $48 \mathrm{~h}$ of storage, although their quality declined significantly $(\mathrm{P}<0.05)$ as post-mortem storage time increased (motility: $83 \pm 1.2,67 \pm 3.0$, and $46 \pm 5.1$; viability: $84.2 \pm 2.4,73 \pm 2.8$, and $66.6 \pm 2.6 \%$ for control, $24 \mathrm{~h}$ and $48 \mathrm{~h}$ group respectively). These data indicate that ram epididymides could be stored at $4^{\circ} \mathrm{C}$ for $48 \mathrm{~h}$ when epididymal spermatozoa cannot be immmediately collected and cryopreserved. These storage conditions might be possible to use for epididymal sperm recovery in wild ruminants.
\end{abstract}

Keywords: epididymal spermatozoa, Freezing, ram, refrigeration

\section{INTRODUCTION}

To conserve the genetic resources of domesticated and wild animals for future generations, we currently maintain living animals or store frozen germ cells, such as spermatozoa, oocytes and embryos, from them. The manpower and cost efficiency of repositories of cryopreserved genetic resources, or gene banks, is now attracting attention. With transgenic animals becoming established in recent years, gene banking has also become important for animal conservation. Protocols for freezing spermatozoa have already been established for many animal species and since the procedure is comparatively simple, it is used fairly frequently. Cryopreservation of spermatozoa thus seems to be a highly suitable method for stocking a gene bank. However, while we can collect and freeze ejaculated spermatozoa from livestock accustomed to the procedure, it is extremely difficult to do this with other animals, particularly wild animals. The epididymis is an organ in which maturing spermatozoa are stored. Since frozenthawed epididymal spermatozoa have fertilization ability in mice (Nakagata, 1992) and pigs (Nagai et al., 1988), we believe that cryopreservation of epididymal spermatozoa is an important method for conservation of animal genetic resources.

However, in order to get good quality samples, sperm collection and processing should be carried out immediately after the death of the animal. This is not always possible, especially regarding wild species. In these circumstances, animal death is generally unpredictable or it happens far away from laboratories and technicians. Thus, storing method is required for temporarily preserving spermatozoa viability when epididymal spermatozoa can not be collected and/or frozen immediately. To date, 
many studies have demonstrated that it is possible to obtain viable gametes postmortem. More than 70 years ago, Walton (1930) recovered spermatozoa capable of fertilizing oocytes from rabbit vas deferens that had been cooled to $15^{\circ}$ or $10^{\circ} \mathrm{C}$ for various times. Live mice have been produced by in vitro fertilization (IVF) of oocytes with spermatozoa retrieved from caudae epididymides of carcasses held at room temperature for $24 \mathrm{~h}$ postmortem (Songsasen et al., 1998). Viable spermatozoa have been recovered from the epididymides of refrigerated mice up to 7 days after death, and live young produced by transfer of embryos derived by IVF with such spermatozoa (An et al., 1999). Although, these studies showed that spermatozoa recovered from postmortem specimens even many hours after death retain their function, there are many dissimilarities between species, possibly due to differences on cold shock endurance of epididymal sperm. This storing method was a promising method not for the conservation of ram genetic resources, but could be used to rescue male germ cells from a suddenly decreased ram of high genetic value. In which, at many farm, however, it is not always possible to collect and freeze epididymal spermatozoa due to lack of technicians and equipment. Therefore, the purpose of this study was to determine whether presumptively live spermatozoa could be recovered from ram epididymides that had been stored at $4^{\circ} \mathrm{C}$ for 48 hours. The characteristic of frozen-thawed epididymal spermatozoa and refrigerated storage of ram spermatozoa, including motility and viability of spermatozoa were measured.

\section{MATERIALS AND METHODS}

\section{Preparation of ram testes}

Six pairs of testes with attached epididymides were obtained at local slaughterhouse. They were transport to the laboratory at room temperature. Immediately upon removal, the organs were washed by isotonic saline supplemented by $100 \mathrm{IU} / \mathrm{ml}$ penicillin and $0.1 \mathrm{mg} / \mathrm{ml}$ streptomycin. From one testes of each pairs, the epididymis was dissected free and spermatozoa were recovered from it to serve as an control group and then cryopreserved (Experiment 1). Its undissected counterpart with the epididymis still attached to the testes was placed into plastic bag and kept at $4^{\circ} \mathrm{C}$ (Experiment 2). The characteristic of spermatozoa of each experiment were assessed for sperm motility and viability. The percentage of motile spermatozoa was determined by microscopic examination on warm stage at $37^{\circ} \mathrm{C}$ at magnification of $\mathrm{x} 400$. The viability of spermatozoa were assessed by a supravital stain with eosin and nigrosin and examined using a bright field microscope (typically using a 40100X objective lens).

\section{Experiment 1}

The characteristic of ram spermatozoa collected from epdidimis immediately after slaughter and the characteristic of those spermatozoa after cryopreserved were measured. Cauda epididymis was dissected free from one testes of each pairs of testes and sliced repeatedly with a scalpel blade to release spermatozoa in a $35 \mathrm{~mm}$ culture dish containing m-PBS at $37^{\circ} \mathrm{C}$. Cryopreservation of control spermatozoa was performed according to the method described by Karja et al. (2002) with minor modifications. The released spermatozoa were washed in m-PBS by centrifugation at $500 \mathrm{x} \mathrm{g}$ for $5 \mathrm{~min}$. The supernatant was removed, and then spermatozoa were examined for characteristics immediately after collection (Collecting group).

The suspension (about $500 \mu \mathrm{L}$ ) of spermatozoa was diluted with $450 \mu \mathrm{L}$ of the first extender which consisted of $8.8 \%$ (wt/vol) lactose, $100 \mu \mathrm{g} / \mathrm{mL}$ penicillin and streptomycin and 20\% (v:v) egg yolk in distilled water. The diluted spermatozoa were equilibrated at $4^{\circ} \mathrm{C}$ for $2 \mathrm{~h}$ (Niwa and Sasaki freezing -1 extender/NSF-1 group). After equilibration for $2 \mathrm{~h}, 250 \mu \mathrm{L}$ of the second extender [the first extender supplemented with $6 \%$ (v:v) glycerol and $1.48 \%$ (v:v) orvus ES paste] was added. The spermatozoa were then equilibrated at $4^{\circ} \mathrm{C}$ for an additional $5 \mathrm{~min}$. At the end of the equilibration period, the same volume $(250 \mu \mathrm{L})$ of the second extender was added at $4{ }^{\circ} \mathrm{C}$ (NSF-2 group). The spermatozoa were immediately loaded into a $0.25 \mathrm{~mL}$ French straw (I.V.M., France). The spermatozoa were frozen by placing the straw on a styrofoam plate in liquid nitrogen vapor for $20 \mathrm{~min}(4 \mathrm{~cm}$ above the surface of liquid nitrogen), and subsequently stored in liquid nitrogen. Then the sperm motility and viability after freezing and thawing (frozenthawed spermatozoa) was assessed (Frozenthawed group). Cryopreserved samples were thawed for $30 \mathrm{~s}$ in a $37^{\circ} \mathrm{C}$ water bath. In this experiment six replicate trials were carried out. 
Experiment 2.

In experiment 2, the quality of sperm samples obtained from ram epididymes stored at $4^{\circ} \mathrm{C}$ at different times after slaughter was evaluated. The undissected counterpart of testes with the epididymis was placed into plastic bag and kept at $4^{\circ} \mathrm{C}$ for 0 (control group), 24 (24 h group) and $48 \mathrm{~h}$ ( $48 \mathrm{~h}$ group) after slaughtered. At the end of each storage time, the spermatozoa were released from the epididimis for assessing of their motility and viability. In this experiment five replicate trials were carried out.

\section{Statistical Analysis}

The percentages of motility and viability of spermatozoa were tested by ANOVA followed by a post hoc, Fisher's protected least significant difference (PLSD) test using the Statview program (Abacus Concepts Inc., Berkeley, CA, USA). Differences $\mathrm{P}<0.05$ were considered significant. The data are shown as means $\pm \mathrm{SD}$.

\section{RESULTS AND DISCUSSION}

The cryopreservation process includes several steps, to form sperm preparation and dilution to the post-thawing maintenance of functional capability: at each of these steps, spermatozoa can lose their ability to function normally. It has been reported that the motility of ejaculate spermatozoa is impaired in the course of cooling to $0^{\circ} \mathrm{C}$ (cold shock), freezing (ice formation and crystallization) and thawing (warm shock, Watson, 1995). As a result of cooling, some workers have reported a decreased motility in spermatozoa. Lengwinat and Blottner (1994) reported a decreased motility and decreased acrosomal integrity after thawing. Therefore, cooled and cryopreserved sperms undergo severe damages that alter their motility and morphology, thus affecting their fertilizing potential (Watson, 1995; Pukazhenthi et al., 2002). This finding was also demonstrated in our present study using epididymal spermatozoa, the motility of spermatozoa was well maintained throughout the dilution procedure $(83.3 \pm 1.1,80 \pm 1.3$, and $80 \pm 1.3 \%$ for collection, NSF-1, and NSF-2 groups respectively); but declined $(\mathrm{P}<0.05)$ after freezing and thawing $(38.3 \pm 3.1 \%)$ (Figure 1). The cryopreservation system using NSF-1 and -2 extenders in this study seems to protect spermatozoa against cold shock, possibly due to the large (18.5 and 20\%) amount of egg yolk in the NSF-I and -II extenders respectively. Egg yolk contains lecithins, and one of them, phosphatidylcholine, was found to protect sperm motility against cold shock (Simpson et al., 1987).

In this study, the quality of sperm samples obtained from ram epididymes stored at $4^{\circ} \mathrm{C}$ at different times after slaughter was also evaluated. Holding spermatozoa at temperatures below body temperature prior cryopreservation is commonly done in many species with acceptable results. Since refrigeration devices are widely available, testicles of animals could be kept at $4^{\circ}$ during its storage. In the present study, the motility of ram spermatozoa collected from epididymides stored at $4^{\circ} \mathrm{C}$ for $24 \mathrm{~h}(67 \pm 3.0 \%)$ or $48 \mathrm{~h}(46 \pm 5.1 \%)$,

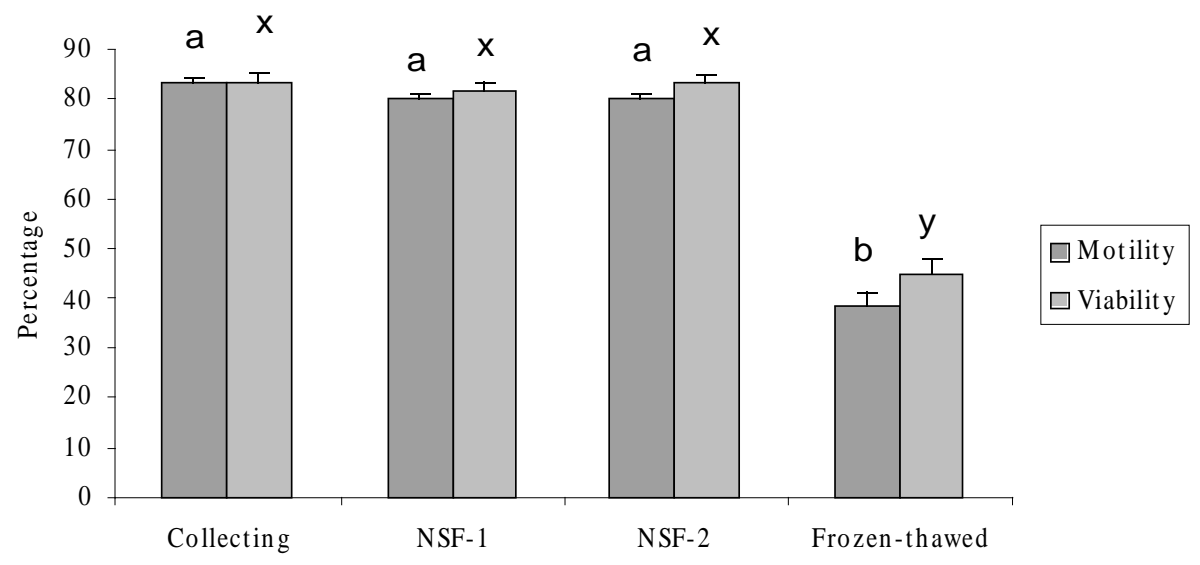

Figure 1. Sperm motility and viability index of control spermatozoa throughout whole cryopreservation procedures. Six replicate trials were carried out. Percentages are expressed as means \pm SEMs. Within each endpoint, bars with different letter (a-b, $x-y)$ represent significantly different $(\mathrm{P}<0.05)$ 
decreased significantly $(\mathrm{P}<0.05)$ in comparison to that of control spermatozoa from non-refrigerated epididymis $(83 \pm 1.2 \%) \quad$ (Figure 2$)$. When epididymides were cooled to $4^{\circ} \mathrm{C}$ and stored for $24 \mathrm{~h}$, the collected spermatozoa showed better motility than cells stored for $48 \mathrm{~h}(\mathrm{P}<0.05)$. Also, viability of the spermatozoa recovered from epididymides stored at $4^{\circ} \mathrm{C}$ decreased significantly within the first $48 \mathrm{~h}$ of refrigeration $(84.2 \pm 2.4,73 \pm 2.8$, and $66.6 \pm 2.6 \%$ for control, $24 \mathrm{~h}$ and $48 \mathrm{~h}$ group respectively).

The beneficial effect of refrigeration on various parameters of sperm quality, especially motility, may be explained by the reduced metabolic rate of sperm cells when they are at $5^{\circ}$ conditions, Garde et al. (1998) found no remarkable variations in the fertilizing ability of ram epididymal samples processed in the first 24 $\mathrm{h}$ after death, noticing a marked diminution in sperm viability for longer periods of time. In red deer (Cervus elaphus) and moufflon (Ovis musimon), Garde et al. (1998) concluded the viability and in vitro fertility (percentage of penetration in hamster oocytes) of sperm decreased when the time between the animal's death and the moment of semen collection increased (up to $40 \mathrm{~h}$ at ambient temperature). On the other hand, Foote (2000) reported that sperm from the epididymides of slaughtered bulls remain fully functional for at least $60 \mathrm{~h}$ at $5^{\circ} \mathrm{C}$ when used

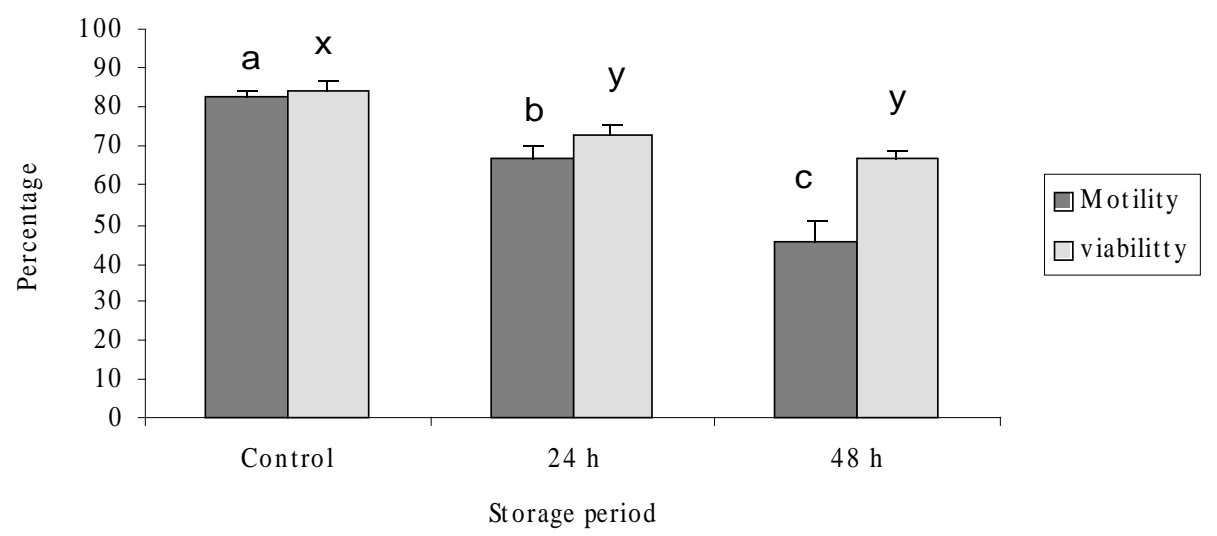

Figure 2. Sperm motility and viability index of ram epididymal spermatozoa collected at various times after storage at $4^{\circ} \mathrm{C}$. Five replicate trials were carried out. Percentages are expressed as means \pm SEMs. Within each endpoint, bars with different letter $(\mathrm{a}-\mathrm{b}$, $\mathrm{x}-\mathrm{y})$ represent significantly different $(\mathrm{P}<0.05)$

C (Lubbe et al., 2000). Whereas, Stechell et al. (1994) suggesting that although the reason for the survival of spermatozoa in epididymides at $4^{\circ} \mathrm{C}$ is unclear, epididymal fluid may contain an unknown cold shock protective factor(s) such lecithin. Moreover, keeping testis and epididymes inside the scrotum should be enough to protect the cauda epididymis from desiccation, consequently avoiding complication in the collection of the sample in the field. In this sense, Sankai et al. (2001) find that motility of mouse epididymal spermatozoa decreases when the storage temperature is increased, suggesting that this effect is related to changes in spermatozoa metabolic activity. In breeding rams, Aguado et al. (1994) reported the preservation of ram sperm stored at room temperature for $0,3,6,9,12$ and $24 \mathrm{~h}$. These authors found semen of better quality, both before and after freezing, when it was collected in the first $3 \mathrm{~h}$ after death. Under similar for artificial insemination. Also, Kikuchi et al. (1998) in pig and Kishikawa et al. (1999) in mice suggest that when valuable male animals die unexpectedly and sperm cryopreservation is not possible immediately, temporal storage of epididymides at $4^{\circ} \mathrm{C}$ may help to preserve the genome of individuals. In the present study, even if the samples have lost its motility because of a long storage, the motility and the viability of storing spermatozoa might be still acceptable (more than $60 \%$ for $24 \mathrm{~h}$ group and $46 \%$ for $48 \mathrm{~h}$ group), so artificial insemination (AI), in vitro fertilization (IVF) or intra cytoplasmic sperm injection (ICSI) could be used to achieve fecundation and pregnancy in the case of valuable individuals or endangered species. Nevertheless, further studies on the fertilizing capacity and the effect of frozen-thawing on ram epididymal spermatozoa, after being refrigerated for many days postmortem, must be carried out in order to 
confirm this possibility.

\section{CONCLUSION}

Motile and viable spermatozoa could be recovered from epididymides up to $48 \mathrm{~h}$ after the animal's death, although the motility and viability of spermatozoa gradually decreased as the storage period was prolonged. The method of storing epididymides described here can be used to conserve male genetic resources in ram when epididymal spermatozoa can not be collected and cryopreserved. Further study combined with AI, IVF, or embryo transfer of IVM-IVF produced embryos is needed to confirm the advantage of this method.

\section{REFERENCES}

Aguado, M.J., J. Garde, J.M. Madriadano, S. Pe 'rez, D. Garrido and V. Montoro. 1994. Congelacio'n post mortem de semen de epid 'dimo de morueco. In: Proceedings of the 7th Jornadas Int Reprod Anim e IA, Murcia, Spain. p. 283.

An, T.Z., S. Wada, K. Edashige, T. Sakurai and M. Kasai. 1999. Viable spermatozoa can be recovered from refrigerated mice up to 7 days death. Cryobiology. 38:27-34.

Foote, R. 2000. Fertilizing ability of epididymal sperm from dead animals. J. Androl. 21:355.

Garde, J., N. Ortiz, A. Garci'a, L. Gallego, C.T. Landete and A. López. 1998. Postmortem assessment of sperm characteristics of the red deer during the breeding season. Arch Androl. 41:195-202.

Karja, N.W.K., T. Otoi, M. Murakami, M. Fahrudin and T. Suzuki. 2002. In vitro maturation, fertilization and development of domestic cat oocytes recovered from ovaries collected at three stages of the reproductive cycle. Theriogenology. 57:2289-2298.

Kikuchi, K., T. Nagai, N. Kashiwazaki, H. Ikeda, J. Noguchi, A. Shimada, E. Soloy and H. Kanekko. 1998. Cryopreservatiion and ensuing in vitro fertilization ability of boar spermatozoa from epididymis stored at $4^{\circ} \mathrm{C}$. Theriogenology. 50:615-623.

Kishikawa, H., H. Tateno and R. Yanagimachi. 1999. Fertility of mouse spermatozoa retrieved from cadavers and maintained at 4 degrees C. J. Reprod Fertil. 116:217-222

Lengwinat, $\mathrm{T}$ and $\mathrm{S}$. Blottner. 1994. In vitro fertilization of follicular oocytes of domestic cat using fresh and cryopreserved epididymal spermatozoa. Anim Reprod Sci. 35:291-301.

Lubbe, K., P. Bartels, I. Kilian, Y. Friedmann and R.A. Godke. 2000. Comparing motility and morphology of horse, zebra and rhinoceros epididymal spermatozoa when cryopreserved with two different cryodiuents or stored at 4 8C. Theriogenology. 53:338 (abstract).

Nagai, T., T. Takahashi, H. Masuda, Y. Shioya, M. Kuwayama, M. Fukushima, S. Iwasaki and A. Hanada. 1988. In-vitro fertilization of pig oocytes by frozen boar spermatozoa. J. Reprod Fertil. 84: 585-591.

Nakagata, N. 1992. Production of normal young following insemination of frozen-thawed mouse spermatozoa into Fallopian tubes of pseudpregnant female. Exp Anim. 41: 519522.

Pukazhenthi, B., R. Spindler, D.E. Wildt, L.M. Bush and J.G. Howard. 2002. Osmotic properties of spermatozoa from felids producing different proportions of pleiomorphism: influenceof adding and removing cryoprotectant. Cryobiology. 44:288-300.

Sankai, T., H. Tsuchiya and N. Ogonuki. 2001. Short-term nonfrozen storage of mouse epididymal spermatozoa. Theriogenology. 55:1759-68.

Simpson, A.M., M.A. Swan and I.G. White. 1987. Susceptibility of epididymal boar sperm to cold shock and protective action of phosphatidylcholine. Gamete Res. 17:355373.

Songsasen, N., J. Tong and S.P. Leibo. 1998. Birth of live mice derived by in vitro fertilization with spermatozoa retrieved up to $24 \mathrm{~h}$ after death. J. exp. Zool. 280:189-196.

Stechell, B.P., A. Maddock and D.E. Brooks. 1994. Anatomy, vasculature, innervation, and fluids of the male reproductive tract. In: Knobil E, Neill JD, Greenwald GS, Markert CL, Pfaff DW (eds), The physiology of Reproduction. New york: Laven Press. 10631175.

Walton, A. 1930. The effect of temperature on the survival in vitro of rabbit spermatozoa obtained from vas deferens. J exp. Biol. 7:201-219.

Watson, P.F. 1995. Recent developments and concepts in the cryopreservation of spermatozoa and the assessment of their postthawing function. Reprod fertile dev. 7:871891. 